DOI 10.37882/2223-2966.2020.10.27

\title{
МОДЕЛИРОВАНИЕ ПЛАМЕПРЕГРАДИТЕЛЯ В РАМКАХ СОЗДАНИЯ МАТЕМАТИЧЕСКОЙ МОДЕЛИ АВАРИЕСТОЙКОЙ ТОПЛИВНОЙ СИСТЕМЫ ВЕРТОЛЁТА
}

\section{SIMULATION OF A FLAME ARRESTER AS PART OF THE CREATION OF A MATHEMATICAL MODEL OF AN ACCIDENT-PROOF FUEL SYSTEM OF A HELICOPTER}

\section{Smagin \\ K. Napreenko K. Starostin}

Summary: The article considers the issue of ensuring fire safety on board a modern helicopter. The purpose and composition of the accident-proof fuel system (AFS) are described. The principle of operation and design of such an AFS aggregate as a flame arrester is analyzed in detail. Its hydraulic calculation was carried out, the distribution fields of the total overpressure, velocity vectors and coolant flow lines are presented as the results. An example of using the data obtained in this calculation to construct a one-dimensional mathematical model of an accident-proof fuel system of a helicopter is described.

Keywords: mathematical model, flame arrester, accident-proof fuel system, helicopter.

\section{Введение}

A варийные ситуации на борту вертолета, результатом которых становятся деформация конструкции топливных баков, разрушения элементов магистралей топливной системы, а также контакт разлитого топлива с нагретыми поверхностями, зачастую являются причиной возникновения пожара [1].

Для его предотвращения применяют целый ряд конструктивных мер, таких как:

- противопожарные перегородки, выполненные из титановых либо стальных листов;

- огнестойкие элементы топливной системы, масляной, воздушной, гидравлической и электрической систем;

- организация охлаждения элементов конструкции двигателя с высокой температурой

- негорючие и самозатухающие материалы в отделке кабины и других отсеков

- и ряд других.

Наиболее остро вопрос обеспечения пожаро- и взры-
Смагин Денис Игоревич

Начальник лаборатории, Московский авиачионный институт (национальный исследовательский университет)

79637587781@yandex.ru

Напреенко Константин Сергеевич

Инженер 2 категории, Московский авиационный институт (национальный исследовательский университет) konaprko@yandex.ru

Старостин Константин Игоревич Ведущий инженер, Московский авиационный институт (национальный исследовательский университет) ki-star1969@yandex.ru

Аннотация: В статье рассмотрен вопрос обеспечения пожарной безопасности на борту современного вертолета. Описаны назначение и состав авариестойкой топливной системы (АСТС). Подробно разобран принцип действия и конструкция такого агрегата АСТС, как пламепреградитель. Произведен его гидравлический расчет, в качестве результатов представлены поля распределения полного избыточного давления, векторы скоростей и линии течения теплоносителя. Описан пример использования данных, полученных при таком расчете для построения одномерной математической модели авариестойкой топливной системы вертолета.

Ключевые слова: математическая модель, пламепреградитель, гидравлические потери, авариестойкая топливная система, вертолет.

вобезопасности относится к авариестойкой топливной системе (АСТС) современного вертолета.

Одним из элементов авариестойкой топливной системы служащим для предотвращения распространения пламени в топливные баки при помощи размещенного внутри его корпуса специального пламядробящего устройства является пламяпреградитель.

Данный агрегат является одним из агрегатов АСТС, создание математической модели и расчет которого необходим для создания комплекса средств математического в совокупности с испытательной установкой для сопровождения процессов проектирования, испытаний и дальнейшей эксплуатации авариестойкой топливной системы (АСТС) современного вертолета.

Выполнением данного проекта занимается МАИ и АО «ОКБ «Кристалл» В рамках реализации постановления Правительства РФ от 09.04.2010 N 218 (ред. от 21.07.2016).

За основу модели взят пламяпреградитель, аналогичный представленному в Патенте № RU 197767 U1, но 
при этом имущий ряд конструктивных дополнений [3]. Общий вид пламяпреградителя приведен на рисунке 1.

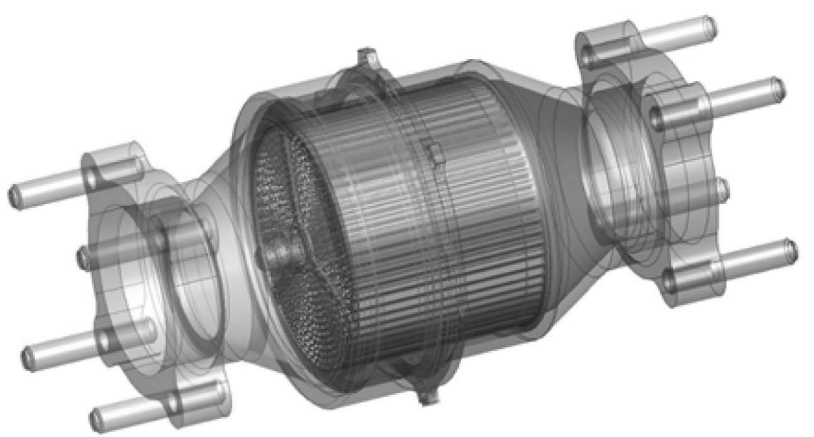

Рис. 1. Пламепреградитель

В качестве основного огнегасящего элемента используется кассета, представляющая собой совокупность либо гофрированных, либо трубчатых собранных в единый узел термостойких элементов, которые образуют дробящие пламя каналы (рисунок 2). За счет дробления пламени происходит увеличение теплоотдачи и угасание пламени.

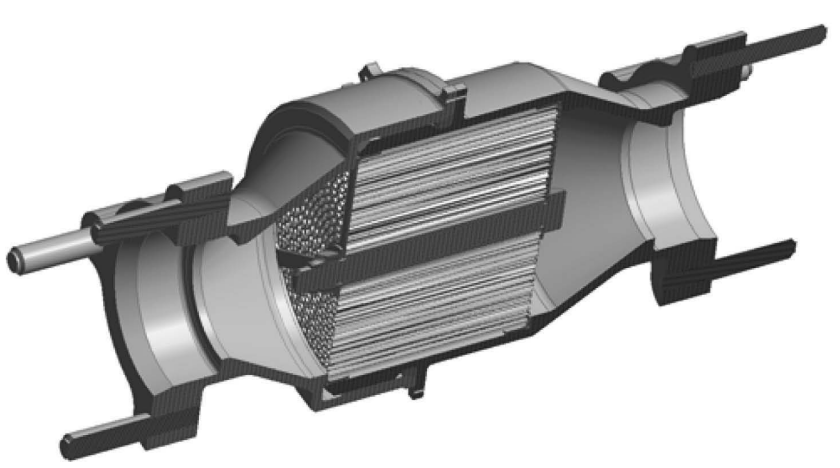

Рис. 2. Пламяпреградитель

При проектировании пламепреградителя важно учитывать такую его характеристику как гидравлическое сопротивление. Одна из основных задач при создании пламепреградителя это выбор его конструкции с оптимальными тепло-гидравлическими характеристиками, а также весогабаритными показателями, что является актуальной проблемой при разработке авариестойких топливных систем. Чтобы решить эту задачу, необходимо обеспечить наилучшее сочетание тепловых, весовых и гидравлических параметров агрегата [4]. Гидравлическое сопротивление агрегата равно величине безвозвратной потери полной энергии при движении теплоносителя по каналам агрегата затраченное на преодоление сил вязкого трения [5].

\section{Определение величины гидравлического сопротивления}

Гидравлическое сопротивление участка можно определить с помощью коэффициента гидравлического сопротивления ל, который характеризует отношение потерь полного давления на участке к величине динами- ческого давления на данном участке:

$$
\Delta P=\zeta \cdot \rho \frac{v^{2}}{2}
$$

где

$\triangle P$ - перепад давления, Па

乙- коэффициент гидравлического сопротивления;

$\rho$ - плотность среды на рассматриваемом участке, кг/м³;

$v$ - скорость движения среды, м/с.

Величины коэффициента 乙 для различных типов участков гидравлического сопротивления приводятся в справочниках или могут быть определены в результате эксперимента.

Гидравлические потери на простых и хорошо изученных геометриях определяются с помощью коэффициентов гидравлического сопротивления и используются в различных областях науки и техники. Однако пламяпреградитель имеет сложную геометрию проточной части, из-за чего корректно определить его гидравлическое сопротивление при помощи данных, имеющихся в литературе, невозможно. В данном случае необходимо применить метод математического моделирования. Современные CFD-коды (Computational fluid dynamics - вычислительная гидродинамика) позволяют дать полное описание процессов с учетом трёхмерной геометрии агрегата с необходимой точностью [6-8].

\section{Расчёт гимравлического сопротивления пламепреграцителя}

Оценка сопротивления конструкции кассеты пламепреградителя проводилась с использованием методов вычислительной гидродинамики (CFD-коды). В расчете рассматривалось течение воздуха без изменения его температурного состояния (изотермический процесс). Была построена тетраэдальная расчетная сетка и выбрана модель турбулентности Shear Stress Transport (SST); в качестве граничных условий задавалось значение расхода воздуха на входе в расчетную модель и давление на выходе из расчетной модели.

Результаты расчета представлены на рисунках 3-5.

Проведение ряда расчетов для различных значений расхода воздуха позволит получить кривую гидравлического сопротивления - зависимость перепада давления от расхода. Такая зависимость необходима для построения одномерной математической модели авариестойкой топливной системы вертолета. Стоит отметить, что применение метода математического моделирования при проектировании бортовых систем летательных аппаратов на сегодняшний день является актуальным направлением в авиационной отрасли [9-13]. Этот метод имеет ряд достоинств, среди которых сокращение вре- 


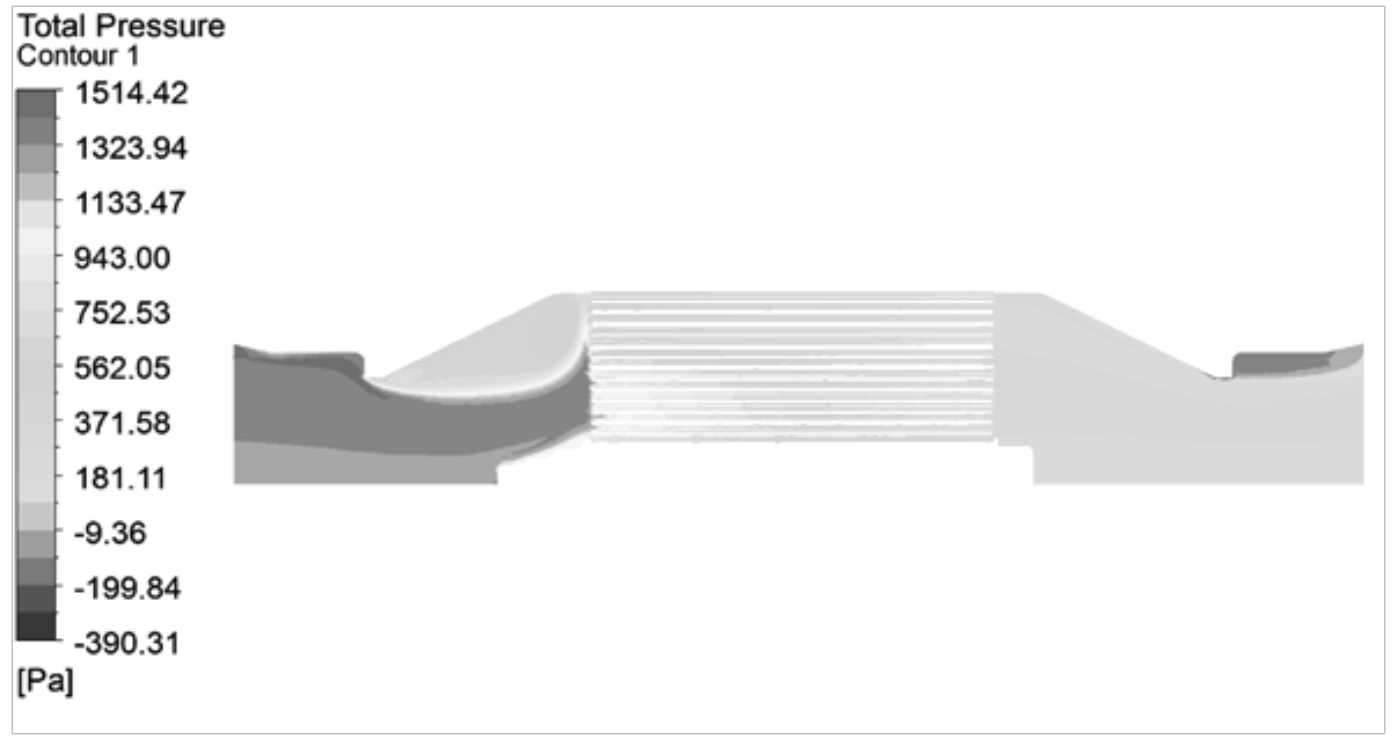

Рис. 3. Распределение избыточного полного давления

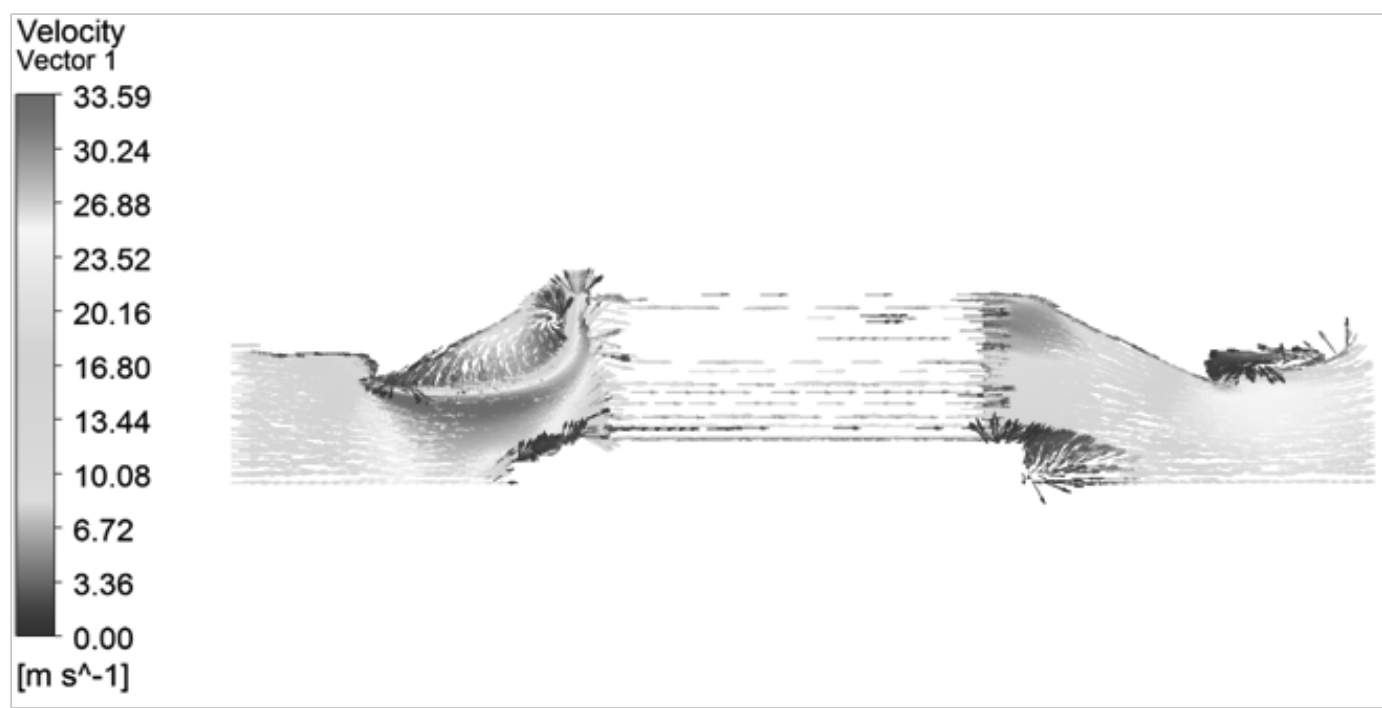

Рис. 4. Распределение векторов скорости

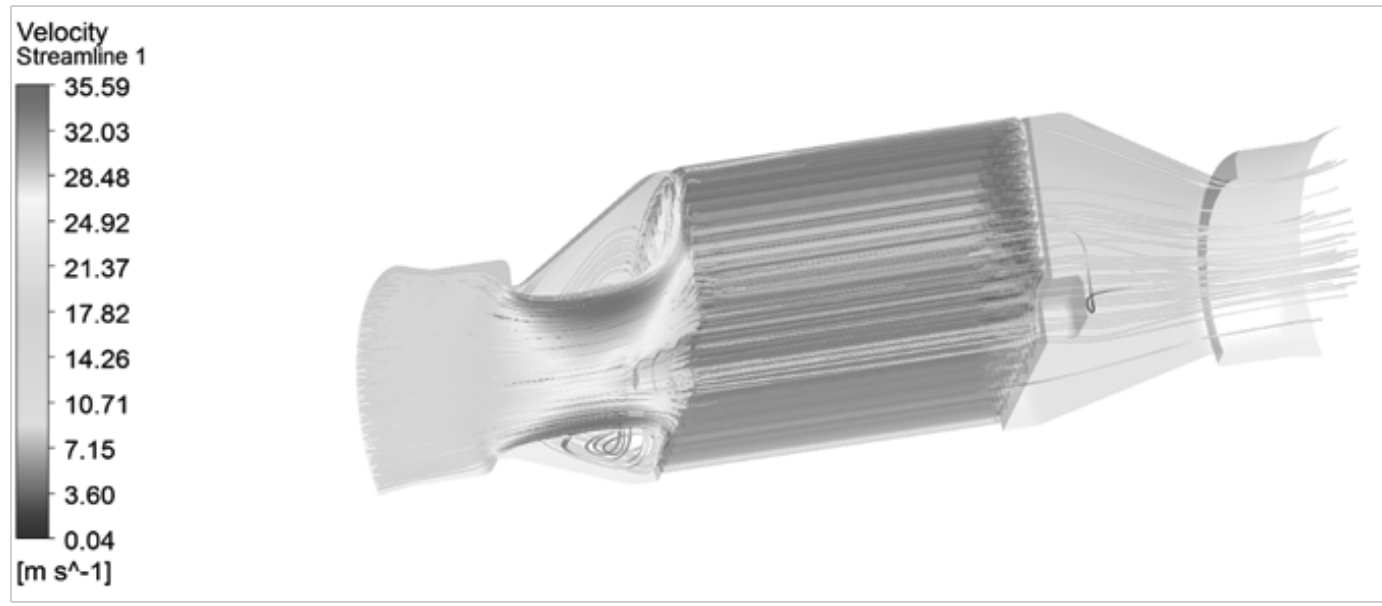

Рис. 5. Распределение потока среды 
менных и финансовых затрат на различных этапах жизненного цикла изделия.

\section{Заключение}

В статье рассмотрен вопрос создания авариестойкой топливной системы для современного вертолета. Подробно рассмотрен один из агрегатов системы пламяпреградитель. Описана возможность получения гидравлической характеристики пламепреградителя с использованием метода вычислительной гидродинамики. Объем данных, полученный при проведении гидравлического расчета при помощи математического моделирования, позволяет не только оценить разработанную конструкцию, но и, при необходимости, произвести оптимизацию конструкторских и технологических решений, например, по критерию гидравлического сопротивления.

Полученные в результате исследования пламепрегралителя данные могут быть использованы в составе комплекса средств математического в совокупности с испытательной установкой для сопровождения процессов проектирования, испытаний и дальнейшей эксплуатации авариестойкой топливной системы (АСТС) современного вертолета. Использование характеристики пламяпреградителя, а также других агрегатов АСТС позволит получать результаты исследования различных режимов работы системы с помощью одномерной модели АСТС с высокой степенью точности.

ЛИТЕРАТУРА

1. Пермяков С.Н., Савельев Е.А. Исследование проблем создания авариестойкой топливной системы вертолета // Известия Самарского научного центра Российской академии наук. 2014. Том 16, № 1 (5).

2. Маковецкий М.Б., Пугачев Ю.Н., Смагин Д.И., Ткаченко И.О. Обеспечение нового качества авиатехники. Проектирование, изготовление и испытания мягких топливных баков авариестойкой топливной системы вертолетов // Качество и жизнь. 2018.

3. Патент № RU 197767 U1 Пламяпреградитель для авариестойкой топливной системы. Режим доступа: https://yandex.ru/patents/doc/ RU197767U1_20200528.

4. Zyazeva T.Y., Smagin D.I., Savelev R.S. A Solution to the Problems of Appearance Optimization for "Flame blocker"-type Units Using Advanced Production Technologies // 2019 IEEE 10th International Conference on Mechanical and Aerospace Engineering.

5. Идельчик И.Е. Справочник по гидравлическим сопротивлениям / Под ред. М.0. Штейнберга. 3-е изд., перераб. и доп. М.: Машиностроение, 1992.672 с: ил.

6. Upendra Rajak, Ruchi Khare, Vishnu Prasad. Flow simulation of elbow draft tube using star CCM+FLOW simulation of elbow draft tube using star ccm + // 4th National Conference on "Recent Innovations in Mechanical Engineering (NCRIME 2K17)".

7. Schesnyak L.E. Modeling of the conjugation of vortex flows with downstream in ANSYS // IOP Conference Series Materials Science and Engineering 675:012026 November 2019. D0I: 10.1088/1757 899X/675/1/012026.

8. Rao M.A. Masood. Tutorial Lobe Pump CFD Simulation with ANSYS CFX. DOI: 10.13140/RG.2.2.17585.89445.

9. Стрелец Д.Ю., Смагин Д.И., Старостин К.И., Савельев Р.С., Напреенко К.С., Сокулер М.С., Паронькин С.В., Сатин А.А. Повышение качества расчета параметров воздуха в пассажирских зонах ближне-среднемагистрального самолета путем взаимодействия одномерного (Simintech) и трехмерного (Логос) программных комплексов // Computational nanotechnology. 2018. № 4. С. 35-40.

10. Смагин Д.И., Старостин К.И., Савельев Р.С., Кобринец Т.А., Сатин А.А. Методика создания динамической математической модели системы нейтрального газа для перспективного самолета в программном комплексе Simintech // Computational nanotechnology. 2018. № 2. C. 21-27.

11. Hong-Xin Wang, Yao-Xing Shang, Jiang-He Jia, Zong-Xia Jiao. Simulation and analysis for users flow requirements of aircraft hydraulic system based on AMESim // Conference: 2016 IEEE/CSAA International Conference on Aircraft Utility Systems (AUS). DOI: 10.1109/AUS.2016.7748165.

12. Mario Maia Neto, Luiz Goes. Use of LMS Amesim Model to Predict Behavior Impacts of Typical Failures in an Aircraft Hydraulic Brake System // Proceedings of 15:th Scandinavian International Conference on Fluid Power. December 2017. D0I: 10.3384/ecp1714429.

13. Jie Tang, Qiang Liu, Jianwei Hu, Jinjian Huo, Liwen Wang. Leakage fault diagnosis method of aircraft landing gear hydraulic cylinder based on wavelet packet // The Journal of Engineering. 2018. DOl: 10.1049/joe.2018.9037.

( С Смагин Денис Игоревич (79637587781@yandex.ru ), Напреенко Константин Сергеевич (konaprko@yandex.ru ), Старостин Константин Игоревич (ki-star1969@yandex.ru).

Журнал «Современная наука: актуальные проблемы теории и практики» 